\title{
Determinants of outcome of vocational rehabilitation
}

\author{
Kristın Siggeirsdottir ${ }^{a, b, *}$, Ragnheidur Dora Brynjolfsdottir ${ }^{a}$, Saemundur Oskar \\ Haraldsson $^{a, c}$,Sigurdur Vidar ${ }^{a}$, Emanuel Geir Gudmundsson ${ }^{a}$, Jon Hjalti Brynjolfsson ${ }^{a}$, Helgi \\ Jonsson $^{\mathrm{a}}$, Omar Hjaltason ${ }^{\mathrm{a}}$ and Vilmundur Gudnason ${ }^{\mathrm{a}, \mathrm{b}, \mathrm{d}}$ \\ a Janus Rehabilitation, Reykjavik, Iceland \\ ${ }^{b}$ Icelandic Heart Association Research Institute, Reykjavik, Iceland \\ ' University of Stirling, Stirling, Scotland, UK \\ ${ }^{\mathrm{d}}$ University of Iceland, Reykjavik, Iceland
}

\section{ABSTRACT}

BACKGROUND: Information regarding the determinants of successful vocational rehabilitation (VR) is scarce.

OBJECTIVE: Investigate whether sex, duration, quality of life and financial circumstances influence the success of VR.

METHODS: The study group consisted of 519 participants, (293 women, 56\%) who finished VR in the period 2000-2014. The group was divided into the following subgroups: dropouts, unsuccessful and successful VR. Data were collected by questionnaire.

RESULTS: Income had the most impact on whether the outcome was successful. Having supplemental income when entering the VR program increased the likelihood of a successful conclusion, odds ratio (OR) 5.60 (95\% CI; 2.43-13.59) (p<0.001), being on sick leave OR 5.02 (95\% CI 1.93-13.79) $(\mathrm{p}<0.001)$ or rehabilitation pension OR 1.93 (95\% CI 1.07-3.52) $(p<0.03)$. The participants in the successful sub-group were older $(p<0.06)$ and stayed in rehabilitation longer $(\mathrm{p}<0.001)$, compared to those who were unsuccessful. However, the effect on OR was limited: 1.03 (95\% CI 1.01-1.06) and 1.04 (95\% CI 1.02-1.07), respectively. 
CONCLUSIONS: For this sample, supplemental income appears to be the most important factor for a successful rehabilitation outcome. Checking financial status at the beginning of the rehabilitation process could minimize financial strain and increase the likelihood of success.

Keywords: Financial income; Quality of life, longitudinal research, mental health, employment, education. 


\section{Introduction}

Vocational rehabilitation is an important, yet young, field of rehabilitation [1], and many aspects have yet to be explored. It is designed to assist long-term sick-listed and unemployed individuals return the workforce [1]. Long-term unemployment or sick-leave might negatively affect different psychological and/or musculoskeletal problems. These problems might make it stressful or even impossible for people who have been off work for more than 12 months to return to work [2]. Vocational rehabilitation is therefore often crucial in assisting individuals to overcome obstacles in their returning to work and gaining a better quality of life (QoL) [3].

According to the World Health Organization (WHO), an individual's QoL is determined by his/her self-perception and place in society as viewed or how others define him/her. QoL is a multidimensional concept and has been defined for various aspects of living, e.g., physical health and social life [4,5]. Poor Health Related QoL (HRQoL) has been associated with the increased use of healthcare services, physical inactivity and a number of diseases as well as mortality [6]. HRQoL might thus be a good indicator of the rehabilitation outcome, whether successful or not. Any significant increase in QoL would therefore suggest successful rehabilitation.

Due to the 2008 financial recession, unemployment in Iceland increased from $3.0 \%$ to 5.4\% in 2013 [7], reducing measured QoL in general by limiting financial resources [4]. Furthermore, the number of people on disability pensions has also been steadily increasing in Iceland. In 1986, 3.5\% of the population were on disability pensions, and in 2012 that proportion had increased to $8.5 \%$ [8]. The majority of disability pension claims were due to psychological and/or musculoskeletal difficulties [8], and a large number of claimants needed vocational rehabilitation. 
A professional multidisciplinary team in vocational rehabilitation has proven to be successful in accommodating the need of these individuals. The team consists of a wide range of professionals (e.g., psychologist, physical therapist, social worker, occupational therapist and physician) working closely together. Their aim is to help each participant achieve long-lasting results [9]. This type of rehabilitation has been slowly increasing in Iceland in response to the situations previously outlined. Even though various VR programs from different countries have been described in the literature [10-13] these programs might not be applicable to other societies or groups of individuals.

The lack of this specific service in Iceland at the turn of the century gave rise to the Janus Rehabilitation Centre (JR). JR's novel approach to rehabilitation has since gained recognition for benefitting people with a variety of severe psychological conditions. JR has thus filled a gap in Iceland where other rehabilitation programs have been unable to provide service. For many people JR is their sole option [14].

Participants in vocational rehabilitation have widely differing requirements and may therefore need a diverse range of approaches [3]. This has yet to be explored as has whether the success of vocational rehabilitation (VR) depends on multiple characteristics, including but not limited to sex, age, financial status or type of condition. Without evidence professionals lack direction when programming for such a diverse range of participants. The demand is for quality VR that is participant-centred, quick and efficient which produces permanent and positive results. JR provides a unique opportunity to explore data gathered since its establishment in 2000 and the outcomes of JR programming.

This present research investigated whether the outcome of vocational rehabilitation is influenced by sex, duration, quality of life and financial circumstances.

The research was approved by the Icelandic National Bioethics Committee, VSNb2014080002/03.07. 


\section{Materials and Methods}

Janus Rehabilitation (JR) started in the year 2000. The philosophy has been the same from the outset. The multidisciplinary approach of JR is holistic. It is based on the belief that knowledge from many different disciplines is needed [14], e.g., Model of Human Occupation [15], Intrinsic Motivation [16] and Cognitive Behavioral Therapy [17], to adapt VR to the participant's needs and, thus, efficiently enable them to be a part of the labour market. Creating an environment which gives participants the opportunity to empower themselves has been shown to be important in successful VR. JR is aware that each individual may need different surroundings where he/she can progress [18]. The professional multidisciplinary team therefore uses five different pathways which are tailored to participants' individual needs.

The term participant is carefully chosen to fit both the educational- and health systems as JR combines both systems. Using the term participants also avoids the stigma which might be connected with the term "patient", implying that people are ill and not in control of their own lives. In JR it is fundamental that every person is a participant in their own path to wellbeing and the belief in successfully becoming a member of the workforce, even if it means changing profession.

Successful outcome was determined by JR experts as attending work or school or applying for work, which was seen as an indication of a fundamental change for the participant. An unsuccessful outcome was when a participant does not reach previously defined successrelated goals despite a full attendance. Dropouts were participants who discontinued their rehabilitation for various unknown reasons. 
JR's multidisciplinary professional team consists of physicians, occupational and physiotherapists, social workers, psychologists, teachers and other professionals, with the aim of providing high quality service [14].

\section{The Program}

The program is participant-centred; each participant is allocated their own coordinator who meets with them regularly. The coordinators in JR are educated as occupational therapists, social workers, physiotherapists or psychologists. In collaboration with the participant, the coordinator governs the rehabilitation process and works with multidisciplinary internal and external team members. The rehabilitation team has broad expertise. Employees within the same profession specialize in different areas to provide the best possible service. According to participants' needs, they are offered different educational courses, and/or treatments where necessary, e.g., for depression or anxiety. There is an emphasis on working to the participant's strength and interests to enable them to return to work or school. JR tries to offer all of its services internally, but if specific expertise is required from elsewhere, it is provided.

JR divides the rehabilitation process into five paths or programs offering various challenges and interventions. The participant is able to change paths when needed. These paths have evolved through experience and are named after the specialized aim they emphasize: the Task Path, the School Path, the Health Path, the Individual Path and the Work Path.

The paths take into consideration the unique needs of each participant and are tailored to his/her capabilities. Within the paths the needs for work training, further education, social training, physical exercise as well as contacts with employers are met.

From the beginning there were no explicit time limits to the rehabilitation process since the participant was often in need of long-term rehabilitation because of psychological disorders. 


\section{Cohort and data}

The majority of the participants were referred by their doctors or else they came directly from the only hospital in the capital city area, Reykjavik, the University National Hospital. Others came from pension or sickness benefit funds or VIRK - the Icelandic Vocational Rehabilitation Fund.

The study group consisted of 519 participants, 293 women and 226 men, who had finished their rehabilitation between January 18, 2000 and January 1, 2015.

Information on social functioning and personal characteristics was collected with a questionnaire where participants could opt out of individual questions. Answers that were not given were listed as "not available" in the statistical analysis. The following variables were used:

Education was divided and organized by stage, each stage indicating the highest educational level attained. Those who had finished primary education had only finished mandatory education as it was during their childhood. For some it was only the first year to the sixth year of primary school, and for others it was ten years of primary education. Vocational certificate included various certificates, such as a license to drive a taxi, operate heavy machinery or even a certified nail specialist. Secondary education included high school or equivalent, while vocational degree included everything requiring at least some secondary education and/or vocational training of some kind. Vocational degree and secondary education were considered equivalent in the analysis since they usually take similar times to complete. College or University stands for those who have earned a diploma or degree from a higher educational institution.

Illness was divided into three categories, based on the International Classification of Diseases (ICD version 10), where musculoskeletal illnesses fall into block M00-M99, and psychological illnesses fall into F00-F99. Other diseases are put into a miscellaneous group. 
Income lists the main source of income of participants. It was divided into five categories. Disability benefit is a permanent pension and varies according to a participant's other income. Social benefit can vary in duration, but a rehabilitation pension never exceeds three years. Sick leave is always temporary and is a percentage of the individual's salary. The duration can be for up to two years. Other income was defined as income without a payroll or known as supplemental income.

Every participant answered a questionnaire at the start of their rehabilitation. The answer options were "Yes" and "No": Have you experienced financial difficulties in the last 12 months? Have you ever abused any illegal substances? Do you suffer from any educational difficulties (e.g. dyslexia)? Are you responsible for a child? Are you married? Are you single? Have you previously been in rehabilitation?

The Icelandic Quality of Life Questionnaire (IQL) was used to assess participants' perceptions of their health-related quality of life [19]. It measures 12 aspects of health-related quality of life. A total score is calculated, and a score of 50 is considered to be in the normal range for the average Icelander. The IQL reliability and validity is acceptable [19, 20, 21].

\section{Statistical Analysis}

The cohort was divided into three categories: successful, unsuccessful and dropout.

To analyze the response variable, two categories, successful or unsuccessful, were used in a stepwise logistic regression. Initially, local minimization of Akaike’s information criterion (AIC) guided the search by adding or removing explanatory variables one by one. The search was then finished by p-value selection, where entrance and exit tolerances are 0.05 and 0.10 , respectively. For a variable that was not a part of the model, if the p-value was equal to or below 0.05 , it was accepted into the model. Similarly, for a variable that was already in the model, if the p-value exceeded 0.10, it was removed from the model. 
The explanatory variables were assumed to be age, length of unemployment, initial measurement of IQL and all the variables shown in Table 1.

At the same time traditional statistical tests (t-tests) were performed on the hypotheses that the difference in means of the dependent variables was equal to 0 for different values of the explanatory variables and either sex.

The data analysis for this paper was generated using modules programmed in Python, an open source programming language, and in R [22].

\section{Results}

Data for 519 participants: 293 women, mean age 35.0 years $( \pm 10.1)$, and 226 men, mean age 36.1 years $( \pm 10.5)$, were available for the analysis.

The cohort was divided into three sub-groups: dropout, unsuccessful and successful. The first group included 43 participants, with a mean age of 32.2 years $( \pm 8.2)$, the second 239 with a mean age of 35.3 years $( \pm 10.2)$ and the third 237 with a mean age of 36.1 years $( \pm 10.5)$ (Table 1).

Tables 1 and 2 list the characteristics of the participants in different groups at the start of rehabilitation. The dropout group suffered significantly from psychological $(\mathrm{p}<0.001)$ and musculoskeletal problems $(\mathrm{p}=0.035)$, compared to the other two groups. A history of drug abuse was significantly more common in this group compared to the others $(p=0.016)$ (Table 2). The dropout group had been unemployed for significantly longer than those completing rehabilitation, regardless of their success $(\mathrm{p}<0.029)$ (Table 1$)$. No significant difference was found between the groups in IQL (Table 1). Due to missing values for the dropout group, further comparison was not possible. 
Tables 1 and 2 do not show much difference in percentages between the unsuccessful and successful groups regarding the length of rehabilitation and other variables except financial status. The latter had the most impact on rehabilitation outcome. See the comparison between the groups in Table 3. Participants who had supplemental income when entering rehabilitation were more likely to have a successful outcome, OR 5.60 (95\% CI;2.43-13.59) $(\mathrm{p}<0.001)$. Those who were on sick leave had OR $5.02(95 \%$ CI 1.93-13.79) $(\mathrm{p}<0.001)$ and rehabilitation pension OR 1.93 (95\% CI 1.07-3.52) $(\mathrm{p}<0.030)$. Age, rehabilitation length and IQL at the beginning of their JR program had a significant effect on success although the effect was very limited with OR; 1.02 (95\% CI 0.99-1.04) ( $\mathrm{p}<0.06), 1.04$ (95\% CI 1.02-1.07) $(\mathrm{p}<0.001)$ and 1.03 (95\% CI; 1.01- 1.05) $(\mathrm{p}<0.001)$, respectively, (Table 3).

In addition to analyzing the difference between unsuccessful and successful participants, the characteristics were compared to see if there were any sex-related differences. Women needed a significantly longer period of rehabilitation compared to men $(\mathrm{p}<0.001)$ even though they had significantly higher IQL at the beginning of their JR programs $(p<0.1 \mathrm{e}-6)$. A significantly higher proportion of men than women had vocational education $(p<0.1 \mathrm{e}-5)$, but more women were university graduates $(\mathrm{p}<001)$, although the overall proportion in the latter category was too small to make any assumptions. No statistical sex-related differences were found regarding successful outcomes ( $\mathrm{p}>0.403)$.

A summary of the cohort's characteristics, as measured by the questionnaire, can be seen in Table 1 and Table 2. 
Table 1.

Quantifiable characteristics by success, where success is defined as working, studying or seeking employment.

\begin{tabular}{|c|c|c|c|c|c|}
\hline & & Mean & Median & SD & $\mathbf{N}$ \\
\hline \multirow[t]{3}{*}{ Age (years) } & Dropout & $2.2^{3}$ & $0.0^{3}$ & 8.2 & 43 \\
\hline & $\begin{array}{l}\text { Unsucces } \\
\text { sful }\end{array}$ & $5.3^{3}$ & $4.0^{3}$ & 10.2 & 239 \\
\hline & $\begin{array}{l}\text { Successf } \\
\text { ul }\end{array}$ & $6.1^{3}$ & $5.0^{3}$ & 10.5 & 237 \\
\hline \multirow[t]{3}{*}{$\begin{array}{l}\text { Length of } \\
\text { unemployment (months) }\end{array}$} & Dropout & $4.8^{4}$ & $\begin{array}{r}3 \\
5.5^{3}\end{array}$ & 45.0 & 38 \\
\hline & $\begin{array}{l}\text { Unsucces } \\
\text { sful }\end{array}$ & $2.0^{3}$ & $2^{2}$ & 30.3 & 237 \\
\hline & $\begin{array}{l}\text { Successf } \\
\text { ul }\end{array}$ & ${ }^{2} 8^{2}$ & $\begin{array}{c}1 \\
6.0\end{array}$ & 28.6 & 235 \\
\hline \multirow[t]{3}{*}{$\begin{array}{l}\text { Length of rehabilitation } \\
\text { (months) }\end{array}$} & Dropout & ${ }^{1} 1^{1}+1$ & $.2^{7}$ & 9.2 & 43 \\
\hline & $\begin{array}{l}\text { Unsucces } \\
\text { sful }\end{array}$ & $\begin{array}{r}1 \\
5.9^{1}\end{array}$ & $\begin{array}{c}{ }^{1} \\
3.7\end{array}$ & 10.4 & 239 \\
\hline & $\begin{array}{l}\text { Successf } \\
\text { ul }\end{array}$ & ${ }^{2}{ }^{2}$ & $9 .{ }^{1}$ & 12.1 & 237 \\
\hline \multirow[t]{3}{*}{ IQL at start } & Dropout & $2.9^{2}$ & $3.0^{2}$ & 10.1 & 40 \\
\hline & $\begin{array}{l}\text { Unsucces } \\
\text { sful }\end{array}$ & $4.6^{2}$ & $5.0^{2}$ & 12.7 & 202 \\
\hline & $\begin{array}{l}\text { Successf } \\
\text { ul }\end{array}$ & $8.0^{2}$ & $9.0^{2}$ & 12.0 & 204 \\
\hline
\end{tabular}

Table 2.

Characteristics by success, where success is defined as working, studying or seeking employment.

\begin{tabular}{|l|l|l|l|l|}
\hline Variables & Dropout & $\begin{array}{l}\text { Not } \\
\text { Success }\end{array}$ & Success & Total \\
\hline N & 43 & 239 & 237 & 519 \\
\hline Sex & & & & \\
\hline -Male & 22 & 106 & 98 & 226 \\
\hline -Female & 21 & 133 & 139 & 293 \\
\hline Education & & & & \\
\hline
\end{tabular}




\begin{tabular}{|c|c|c|c|c|}
\hline -Other & 1 & 9 & 12 & 22 \\
\hline -Non education & 6 & 15 & 3 & 24 \\
\hline -Primary & 27 & 147 & 141 & 315 \\
\hline -Secondary & 6 & 24 & 29 & 59 \\
\hline -Vocational certificate & 1 & 4 & 6 & 11 \\
\hline -Vocational degree & 1 & 27 & 29 & 57 \\
\hline -University & 0 & 13 & 14 & 27 \\
\hline -Not available & 1 & 0 & 3 & 4 \\
\hline \multicolumn{5}{|l|}{ Illness } \\
\hline -Psychological & 36 & 160 & 151 & 347 \\
\hline -Musculoskeletal & 5 & 62 & 67 & 134 \\
\hline -Other & 2 & 17 & 19 & 38 \\
\hline \multicolumn{5}{|l|}{ History of drug abuse } \\
\hline -Yes & 20 & 75 & 57 & 152 \\
\hline$-\mathrm{No}$ & 18 & 81 & 84 & 183 \\
\hline --Not available & 5 & 83 & 96 & 184 \\
\hline \multicolumn{5}{|l|}{ Carer of children } \\
\hline -Yes & 2 & 107 & 99 & 208 \\
\hline -No & 2 & 85 & 100 & 187 \\
\hline --Not available & 39 & 47 & 38 & 124 \\
\hline \multicolumn{5}{|c|}{ Previously in rehabilitation } \\
\hline -Yes & 2 & 115 & 126 & 243 \\
\hline -No & 1 & 98 & 90 & 189 \\
\hline --Not available & 40 & 26 & 21 & 87 \\
\hline \multicolumn{5}{|l|}{ Financial Difficulties } \\
\hline -Yes & 34 & 151 & 137 & 322 \\
\hline -No & 0 & 62 & 78 & 140 \\
\hline --Not available & 9 & 26 & 22 & 57 \\
\hline \multicolumn{5}{|l|}{ Housing Options } \\
\hline -Owner & 1 & 52 & 58 & 111 \\
\hline -Living w/relative & 1 & 25 & 39 & 65 \\
\hline
\end{tabular}




\begin{tabular}{|c|c|c|c|c|}
\hline -Renting & 1 & 87 & 79 & 167 \\
\hline --Not available & 40 & 75 & 61 & 176 \\
\hline \multicolumn{5}{|l|}{ Income } \\
\hline -Disability benefit & 6 & 64 & 40 & 110 \\
\hline -Rehabilitation pension & 11 & 99 & 100 & 210 \\
\hline -Sick leave & 1 & 15 & 22 & 38 \\
\hline -Social benefit & 13 & 25 & 14 & 52 \\
\hline -Student loan & 0 & 0 & 3 & 3 \\
\hline -Unemployment benefits & 1 & 2 & 1 & 4 \\
\hline -Wage & 0 & 2 & 4 & 6 \\
\hline -Other (supplemental) & 5 & 14 & 37 & 56 \\
\hline --Not available & 6 & 18 & 16 & 40 \\
\hline \multicolumn{5}{|l|}{ Relationship Status } \\
\hline -Single & 2 & 136 & 122 & 260 \\
\hline -Married/partnership & 2 & 55 & 80 & 137 \\
\hline --Not available & 39 & 48 & 35 & 122 \\
\hline \multicolumn{5}{|l|}{ Educational difficulties } \\
\hline -Yes & 12 & 46 & 37 & 95 \\
\hline -No & 27 & 114 & 108 & 249 \\
\hline --Not available & 4 & 79 & 92 & 175 \\
\hline
\end{tabular}


Table 3.

Stepwise logistic regression model showing OR for predicting vocational rehabilitation success, where success is defined as working, studying or seeking employment.

\begin{tabular}{|lcc|}
\hline & OR $(95 \%$ CI $)$ & p-value \\
\hline Age & $1.02(0.99,1.04)$ & 0.060 \\
\hline Rehabilitation length & $1.04(1.02,1.07)$ & 0.000 \\
\hline IQL baseline & $1.03(1.01,1.05)$ & 0.001 \\
\hline Income, supplemental & $5.60(2.43,13.59)$ & 0.000 \\
\hline Income, rehabilitation & $1.93(1.07,3.52)$ & 0.030 \\
\hline Income, sick leave & $5.02(1.93,13.79)$ & 0.001 \\
\hline
\end{tabular}

\section{Discussion}

The effect of different factors on the results of VR was evaluated based on data collected from 519 participants in JR over a 14-year period. JR has based the rehabilitation on the same philosophy during the whole period. The participants had similar problems, with mental- and skeletal problems dominating. The results highlight the importance of the participants' financial security during their VR and might be used to improve some VR programs by including financial literacy by education.

Results showed that supplemental income was the determining factor for the participants' success in their rehabilitation. While these results pertain to Icelandic society, similar outcomes might be expected in the other Nordic countries which have similar social security models and welfare systems [23]. The results must, however, be interpreted with caution with respect to other types of welfare systems.

In Iceland today it is most common for VR participants to be dependent on governmental benefits and pensions, but these benefits and pensions are generally not enough to provide secure incomes above the poverty line [24]. Low benefits and pensions, which are based on 
the average income in Iceland, are likely to negatively affect many individuals in these circumstances. This in turn leads to difficulties in making ends meet and therefore increases the likelihood of losing focus on VR. Supplemental income might therefore be critical for VR participants to feel financially secure. Thus, the successful group might have had the advantage of staying more focused on their rehabilitation than the unsuccessful group. If so, the successful group in this sense had a better foundation for success.

It has been noted that social and occupational status are important factors when predicting successful rehabilitation, where higher status is associated with a greater likelihood of entering the workforce. This observation might be connected with our results as individuals who have higher status in society usually have greater economic stability and perhaps continuing connections to industry [3] and are therefore more likely to succeed in VR.

Our results confirm the complexity of rehabilitating some individuals with psychological problems [3]. This group has often been neglected given the stigma associated with their conditions and thus inhibits them from entering the workforce. [25].

Although this study could not draw conclusions on the dropout group, the clues from its characteristics show a higher percentage of participants with psychological problems compared to the other sub-groups. Further investigation is needed to predict the likelihood of dropping out, based on certain characteristics as well as detailed psychological histories.

The fact that men had significantly lower initial IQL than women, but experienced more rapid IQL improvement and needed less time for rehabilitation is indeed of interest in VR. Many sex-related differences are already well documented in the literature. For example, women are known to rate their QoL lower than men [26], which could indicate that women might need more attention and/or support during the rehabilitation process. 
The strength of the research presented here is that the data were gathered over a 14-year period from more than 500 participants, similarly divided between the sexes and with almost identical median age and age range. This potentially provides a comprehensive view of what could make or break a successful rehabilitation outcome. It should be noted that the cohort in this sample limits generalization because it only represents a subset of those needing and entering VR after a long time away from work. These individuals go through a thorough screening process, evaluating whether they are eligible for JR rehabilitation, and severe cases are admitted. Short-term rehabilitation participants and those who are still integrated with the workforce do not enter JR and were therefore excluded from this research.

The next step would be to replicate the present study, using other methods, such as in-depth interviews with those who did not succeed in their rehabilitation. The impact of an individual's psychological condition on their success is another important factor that needs to be further investigated along with quality of life.

Everyone has different needs which must be met to enable successful participant-centred VR to occur. The results of this study indicated that supplemental income is likely critical for those participants in VR who have to survive on governmental benefits and pensions. This is an important finding that should be taken into account in public policy development as VR has been shown to be economically worthwhile for the entire society [14]. This result demonstrates the importance of proper financial support for participants throughout the VR process.

\section{Acknowledgements}

This study was partially funded by the Icelandic VIRK - Vocational Rehabilitation Fund. 


\section{References}

[1] Marnetoft S, Selander J, Bergroth A, Ekholm J. Factors associated with successful vocational rehabilitation in a Swedish rural area. Journal of Rehabilitation Medicine. 2001; 33(2): 71-78.

[2] Øyeflaten I, Hysing M, Eriksen HR. Prognostic factors associated with return to work following multidisciplinary vocational rehabilitation. Journal of Rehabilitation Medicine. 2008; 40(7): 548-554.

[3] Russinova Z, Rogers E, Ellison M. Predictors of financial self-sufficiency among Social Security beneficiaries with psychiatric disabilities. Journal of Vocational Rehabilitation. [Online] 2013; 38: 49-66. Available from: doi:10.3233/JVR-120620 [Accessed: 4 July 2014]. [4] World Health Organization. WHOQOL: Measuring quality of life World health organization: Division of mental health and prevention of substance abuse. 1997.

[5] Hagerty MR, Cummins RA, Ferriss AL, Land K, Michalos AC, Peterson M, Sharpe A, Sirgy J, Vogel J. Quality of life indexes for national policy: Review and agenda for research. Social indicators research. [Online] 2001; 55(1): 1-96. Available from: doi:

10.1023/A:1010811312332 [Accessed: 18 November 2015].

[6] Djärv T, Wikman A, Johar A, Lagergren P. Poor health-related quality of life in the Swedish general population: The association with disease and lifestyle factors. Scandinavian journal of public health. 2013.

[7] Statistics Iceland. Wages, income and labour market. [Online] Available from: http://www.statice.is/Statistics/Wages,-income-and-labour-market/Labour-market [Accessed: 27 July 2014].

[8] Social Insurance Administration. Invalidity and rehabilitation pensioners as well as invalidity allowance recipients 1986-2012. 2013. 
[9] Chamberlain MA, Moser VF, Ekholm KS, O’Connor RJ, Herceg M, Ekholm J. Vocational rehabilitation: an educational review. Journal of rehabilitation medicine: official journal of the UEMS European Board of Physical and Rehabilitation Medicine. 2009; 41(11): 856-69. [10] Palsdottir AM, Grahn P, Persson D. Changes in experienced value of everyday occupations after nature-based vocational rehabilitation. Scandinavian journal of occupational therapy. 2014; 21(1): 58-68.

[11] Markussen S, Røed K. The impacts of vocational rehabilitation. Labour Economics. [Online] 2014; 31: 1-13. Available from: doi:10.1016/j.labeco.2014.08.001 [Accessed: 25 Oktober 2015].

[12] Joosen MCW, Frings-Dresen MHW, Sluiter JK. Long-term outcomes following vocational rehabilitation treatments in patients with prolonged fatigue. International journal of behavioral medicine. 2013; 20(1): 42-51.

[13Æ] Bio DS, Gattaz WF. Vocational rehabilitation improves cognition and negative symptoms in schizophrenia. Schizophrenia research. [Online] 2011; 126(1): 265-269. Available from: doi:10.1016/j.schres.2010.08.003 [Accessed: 22 Oktober 2015]. [14] Siggeirsdottir K, Alfredsdottir U, Einarsdottir G, Jonsson BY. A new approach in vocational rehabilitation in Iceland: preliminary report. Work. 2004; 22(1): 3-8.

[15] Kielhofner G. A model of human occupation: Theory and application. $3^{\text {rd }}$ ed. Baltimore: Lippincott Williams \& Wilkins; 2002.

[16] Siegert RJ, Taylor WT. Theoretical aspects of goal-setting and motivation in rehabilitation. Disability and Rehabilitation. 2004; 26(1):1-8.

[17] Butler AC, Chapman JE, Forman EM, Beck AT. The Empirical Status of Cognitivebehavioral Therapy: A Review of Meta-analyses. Clinical Psychology Review. 2006; 26(1): $17-31$. 
[18] van Hal LB, Meershoek A, Nijhuis F, Horstman K. The 'empowered client’in vocational rehabilitation: the excluding impact of inclusive strategies. Health Care Analysis. 2012; 20(3): 213-230.

[19] Bjornsson JK, Tomasson K, Ingimarsson S, Helgason T. Health-related quality of life of psychiatric and other patients in Iceland: Psychometric properties of the IQL. Nordic Journal of Psychiatry. 1997; 51(3): 183-191.

[20] Helgason T, Bjornsson JK, Tomasson K, Ingimarsson S. Health-related quality of life. [Icelandic] Laeknabladid. 1997; 83(7): 492-502.

[21] Helgason T, Bjornsson JK, Tomasson K, Grétarsdottir E. Health-related quality of life among Icelanders. [Icelandic] Laeknabladid. 2000; 86(4): 251-257.

[22] R Development Core Team. R: A language and environment for statistical computing. Vienna, Austria: R Foundation for Statistical Computing; 2008. Available from: http://www.R-project.org/ [Accessed: 1st January 2015].

[23] Kausto J, Miranda H, Martimo KP, Viikari-Juntura E. Partial sick leave—review of its use, effects and feasibility in the Nordic countries. Scandinavian Journal of Work, Environment \& Health. [Online] 2008; 34(4): 239-249. Available from: doi:10.5271/sjweh.1266 [Accessed: 27 June 2014].

[24] Traustadottir R, Bjornsdottir K, Rice J, Birgisson K, Smith EKo. Fatcekt og felagslegar adstaedur oryrkja. University of Iceland and the Organization of Disabled in Iceland. [Online] 2011. Available from: http://fotlunarfraedi.hi.is/sites/fotlunarfraedi.hi.is/files/Fataekt_og_felagslegar_adstaedur_dro g.pdf [Accessed: 27 June 2014].

[25] Crowther R, Marshall M, Bond G, Huxley P. Vocational rehabilitation for people with severe mental illness. Cochrane Database of Systematic Reviews. [Online] 2001;(2): CD003080. Available from: doi: 10.1002/14651858.CD003080 [Accessed: 25 March 2015]. 
[26] Kirchengast S, Haslinger B. Gender differences in health-related quality of life among healthy aged and old-aged Austrians: cross-sectional analysis. Gender Medicine. 2008; 5(3): 270-278. 